\title{
In vitro study comparing the efficacy of the water-soluble HSP90 inhibitors, 17-AEPGA and 17-DMAG, with that of the non-water-soluble HSP90 inhibitor, 17-AAG, in breast cancer cell lines
}

\author{
TARIK GHADBAN $^{1 *}$, ANDRÉ JESSEN $^{1 *}$, MATTHIAS REEH $^{1}$, JUDITH L. DIBBERN ${ }^{1}$, \\ SVEN MAHNER ${ }^{2,3}$, VOLKMAR MUELLER ${ }^{2}$, ULRICH F. WELLNER ${ }^{4}$, \\ CENAP GÜNGÖR ${ }^{1}$, JAKOB R. IZBICKI ${ }^{1}$ and YOGESH K. VASHIST ${ }^{1,5}$
}

\begin{abstract}
${ }^{1}$ Department of General, Visceral and Thoracic Surgery and ${ }^{2}$ Gynecology Department and Clinic, University Medical Center Hamburg-Eppendorf, D-20246 Hamburg; ${ }^{3}$ Department of Gynecology and Obstetrics, University of Munich, 80337 Munich; ${ }^{4}$ Clinic for Surgery, University Clinic of Schleswig-Holstein, Campus Lübeck, D-23538 Lübeck, Germany; ${ }^{5}$ Department of Visceral Surgery, Kantonsspital Aarau AG, CH-5001 Aarau, Switzerland
\end{abstract}

Received March 24, 2016; Accepted July 22, 2016

DOI: $10.3892 / \mathrm{ijmm} .2016 .2696$

\begin{abstract}
Heat shock protein (HSP) 90 has emerged as an important target in cancer therapeutics. Diverse HSP90 inhibitors are under evaluation. The aim of the present study was to investigate the growth inhibitory effects of the newly developed water-soluble HSP90 inhibitors, 17-[2-(Pyrrolidin1-yl)ethyl]amino-17-demethoxygeldanamycin (17-AEPGA) and 17-dimethylaminoethylamino-17-demethoxygeldanamycin (17-DMAG), compared to that of the non-water-soluble HSP90 inhibitor, 17-allylamino-17-demethoxygeldanamycin (17-AAG). The anti-proliferative effects of the 3 drugs on the human breast cancer cell lines, MCF-7, SKBR-3 and MDA-MB-231, were examined in vitro. In addition, tumor progression factors, including human epidermal growth factor receptor 2 (HER2), epidermal growth factor receptor 1 (EGFR1) and insulin-like growth factor type 1 receptor (IGF1R), as well as apoptotic markers were analysed. We found a time- and dose-dependent effect in all the tested cell lines. The effects of 17-AEPGA and 17-DMAG were equal or superior to those of 17-AAG. The 50\% growth inhibition concentration was $<2 \mu \mathrm{M}$ for the water-soluble compounds following $72 \mathrm{~h}$ of exposure. The significant inhibition of HER2, EGFR1 and IGF1R protein expression was already evident at the concentration of $1 \mu \mathrm{M}$. Apoptosis was examined by caspase-3 and poly(ADP-ribose)
\end{abstract}

Correspondence to: Dr Yogesh K. Vashist, Department of General, Visceral and Thoracic Surgery, University Medical Center HamburgEppendorf, Martinistrasse 52, D-20246 Hamburg, Germany

E-mail: vashist@uke.de; yogesh.vashist@ksa.ch

${ }^{*}$ Contributed equally

Key words: heat shock protein 90, breast neoplasms, 17-AAG, 17-AEP-GA, 17-DMAG polymerase (PARP) assay at the concentration of $1 \mu \mathrm{M}$ of the inhibitors. HSP70 was upregulated, but HSP27 expression was not affected. Our data indicate that 17-AEPGA and 17-DMAG are highly active in breast cancer cell lines and may help to overcome the delivery issues associated with the use of 17-AAG.

\section{Introduction}

Breast cancer (BC) is the most common malignant disease affecting women. Almost every eighth woman will suffer from this disease during her life (1). Multimodal therapy comprising surgery, radiotherapy, chemotherapy, endocrine therapy and targeted therapy is the standard approach for the treatment of $\mathrm{BC}(2,3)$. Advances in our understanding of the crucial pathways and factors involved in the development and progression of $\mathrm{BC}$ have led to the establishment of predictive factors and targeted therapies for BC (4). However, targeted therapies are mostly effective specifically towards a single factor or pathway and acquired resistance during therapy is a phenomenon often observed in the clinic $(5,6)$. Oncogene switching or the reactivation of signaling pathways by upstream activators leading to the reactivation of downstream signaling pathways counteract all efforts to prevent tumor growth and progression in such a setting. Therefore, a simultaneous targeting of multiple effectors and pathways by a single agent represents a promising therapeutic approach.

Heat shock protein (HSP)90 is a key modulator of post-translational protein folding and has emerged as a target in anticancer therapy in recent years. HSP90 is ubiquitously expressed, but is highly active only in tumor tissue. HSP90 belongs to the family of chaperones and ensures the maturation of a wide range of effectors, so-called client proteins (CPs), which are involved in cell growth, differentiation and survival $(7,8)$. In $\mathrm{BC}$ in particular, HSP90 is a very promising therapeutic target, as human epidermal growth factor receptor 2 (HER2), estrogen receptor (ER) and progesterone receptor (PR) are known CPs of HSP90 (9). Furthermore, the phosphatidyl-inositol pathway 
that is regulated by AKT (AKR mouse thymoma kinase), a CP of HSP90, has been shown to be involved in the resistance of $\mathrm{BC}$ to chemotherapy (10). In a previous study using a xenograft model, the inhibition of HSP90 was shown to be associated with the modulation of angiogenesis (11) and HSP90 expression has been reported to correlate with a poor outcome in BC (12).

The function of HSP90 is dependent upon ATP. The natural ansamycin antibiotic, geldanamycin, binds to the ATP binding site at the N-terminus of HSP90, inhibiting the ATPase activity of HSP90, which leads to the degradation of the CP (13); therefore, many oncogenic signals can be blocked simultaneously by the inhibition of HSP90 (14). The well-known semi-synthetic derivate, 17-allylamino-17-demethoxygeldanamycin (17-AAG), has undergone phase II/III clinical trials (26). However, the lack of solubility in physiological fluids makes formulation for clinical delivery a challenge and limits its clinical use. In an aim to couneract this problem, new water-soluble geldanamycin derivates have been developed, such as 17-dimethylaminoethylamino-17-demethoxygeldanamycin (17-DMAG) and 17-[2-(Pyrrolidin-1-yl)ethyl]amino17-demethoxygeldanamycin (17-AEPGA) (15-18).

In the present study, we compared the growth inhibitory effects of the water-soluble HSP90 inhibitors, 17-DMAG and 17-AEPGA, to those of 17-AAG (not water soluble) on 3 different human $\mathrm{BC}$ cell lines expressing clinically relevant targets (MCF-7, SKBR-3 and MDA-MB-231) in vitro. Furthermore, we examined the effects of HSP90 inhibition at the molecular level focusing on known BC survival and progression factors, such as HER2, epidermal growth factor receptor 1 (EGFR1) and insulin-like growth factor type 1 receptor (IGF1R). In addition, other heat shock proteins, such as HSP70 and HSP27, relevant to HSP90 inhibition $(19,20)$, were analysed.

\section{Materials and methods}

Compounds. For in vitro experiments, 17-DMAG (cat. no. ant-dgl) and 17-AEPGA (cat. no. ant-egl-1) (both from InvivoGen, San Diego, CA, USA) were dissolved in water to a stock concentration of $1 \mathrm{mM}$ and used at final concentrations ranging from 0.1 to $10 \mu \mathrm{M}$. 17-AAG (cat. no. ant-agl; InvivoGen) was dissolved in DMSO to a stock concentration of $1 \mathrm{mM}$ and the same final concentrations $(0.1-10 \mu \mathrm{M})$ were used. The stock solutions were stored at $-20^{\circ} \mathrm{C}$.

Cell lines. The established human BC cell lines, MCF-7, SKBR-3 and MDA-MB-231, were obtained from the American Type Culture Collection (ATCC, Manassas, VA, USA) and cultured in RPMI-1640 medium (cat. no. 72400-021) supplemented with $10 \%$ fetal calf serum (cat. no. 100500-064), $1 \%$ vol/vol penicillin/streptomycin (cat. no. 15140-122) (all from Gibco, Carlsbad, CA, USA) and $1 \% \mathrm{vol} / \mathrm{vol}$ gentamycin $(10 \mathrm{mg} / \mathrm{ml})$ (cat. no. AG A2712; Biochrom AG, Cambridge, UK). The cells were incubated at $37^{\circ} \mathrm{C}$ in a humidified atmosphere containing $5 \% \mathrm{CO}_{2}$. For cell line authentication, a short tandem repeat (STR) DNA profile is used by the cell bank, and the cells were passaged $<6$ months following receipt in our laboratory.

The MCF-7 BC cell line was cultured from a 69-year-old Caucasian woman in 1979 and is characterized by the presence of ER and PR and the lack of HER2 overexpression. The SKBR-3 BC cell line was derived from a 43-year-old Caucasian woman at Memorial Sloan-Kettering Cancer Center in 1970, and it is characterized by HER2 overexpression and the lack of ER and PR expression. The MDA-MB-231 BC cell line was obtained from a 51-year-old Caucasian woman in 1973, by Dr R. Calleau at the University of Texas MD Anderson Cancer Center and has no expression of PR, ER or HER2.

Evaluation of cell doubling time and determination of $50 \%$ cell growth inhibition $\left(G I_{50}\right)$. The anti-proliferative activity of all 3 tested HSP90 inhibitors was determined in vitro using the 3-(4, 5-dimethylthiazol-2-yl)-2, 5-diphenyl-tetrazolium bromide colorimetric method, also known as the MTT reduction assay. This assay is based on the ability of viable cells to reduce MTT-tetrazolium salt into MTT-formazan by the mitochondrial enzyme succinate-dehydrogenase.

Before initiating the proliferation assay, the cell doubling time of each tested cell line was evaluated by MTT assay. Subsequently, the MCF-7, SKBR-3 and MDA-MB-231 cancer cells were cultured in 96-well microtiter plates and seeded at pre-determined densities. Ensuring cell confluence rates of $>60 \%$, fresh medium with or without each HSP90 inhibitors was added at various concentrations for 1, 2 or 3 doubling times. Subsequently, $12.5 \mathrm{ml}$ of an MTT solution in medium $(5 \mathrm{mg} / \mathrm{ml}$ MTT; Sigma Chemical Co., St. Louis, MO, USA) was added for $3 \mathrm{~h}$. The medium was removed and the MTT-formazan crystals were solubilised by the addition of DMSO (100 ml/well). The absorbance was determined at $562 \mathrm{~nm}$. The drug concentration inhibiting $50 \%\left(\mathrm{IC}_{50}\right)$ growth compared to the untreated cells was calculated.

Cell proliferation assay. The MCF-7, SKBR-3 and MDA-MB-231 cancer cells were harvested by trypsinization, counted and $100 \mu \mathrm{l}$ of cell suspension was filled in each well of 96-well plates at concentrations of $10 \times 10^{3}$ cells/well. Ensuring cell confluence rates of $>60 \%$, fresh medium with or without 17-AAG, 17-DMAG and 17-AEPGA was added at concentrations from 0.1 to $10 \mu \mathrm{M}$ for 48 or $72 \mathrm{~h}$. MTT assay was performed as described above. The results were expressed as a percentage of the control. The absorbance of the control (cell culture without any treatment) corresponds to $100 \%$ MTT reduction. Six independent experiments were performed for each cell line and the data are presented as the means \pm SD.

Western blot analysis. To verify the effects of HSP90 inhibition at the molecular level, particularly at the protein level, western blot analyses of all 3 human BC cell lines following treatment with 17-AAG, 17-AEPGA and 17-DMAG were performed.

For western blot analysis, $5 \mathrm{ml}$ of cell suspension with a density of $0.6 \times 10^{6}$ cells $/ \mathrm{ml}$ was used to fill the dishes $6 \mathrm{~cm}$ in diameter followed by incubation overnight until $>60 \%$ confluence was reached. The cells were then treated with 17-AAG, 17-AEPGA or 17-DMAG at concentrations of 1 and $5 \mu \mathrm{M}$ for $24 \mathrm{~h}$. After $24 \mathrm{~h}$, the cells were washed with Dulbecco's phosphate-buffered saline (DPBS) (cat. no. 14190; Gibco) and harvested with EDTA (cat. no. L2113; Biochrom AG). The cells were then lysed in a solution comprising lysis buffer, protein inhibitor and benzonase. The protein content was determined using the BCA protein assay kit (Pierce/Thermo Fisher Scientific Inc., Rockford, IL, USA) and equal amounts of protein (30 $\mu \mathrm{g} /$ volume) were loaded onto a $12 \%$ acrylamide gel containing $\mathrm{H}_{2} \mathrm{O}, 30 \%$ acrylamide/ 
Table I. Calculated $\mathrm{GI}_{50}$ values for all 3 inhibitors in all 3 cell lines tested.

\begin{tabular}{lccccccrr}
\hline Cell line & $\begin{array}{c}\text { 17-AAG } \\
48 \mathrm{~h}(\mu \mathrm{M})\end{array}$ & SE & $\begin{array}{c}\text { 17-AEPGA } \\
48 \mathrm{~h}(\mu \mathrm{M})\end{array}$ & SE & P-value $^{\mathrm{a}}$ & $\begin{array}{r}\text { 17-DMAG } \\
48 \mathrm{~h}(\mu \mathrm{M})\end{array}$ & SE & P-value $^{\mathrm{a}}$ \\
\hline MCF-7 & 5.77 & 22.56 & 4.40 & 4.43 & 0.95 & 3.11 & 10.13 & 0.93 \\
SKBR-3 & 2.43 & 12.51 & 2.47 & 6.28 & 1.00 & 1.71 & 2.17 & 0.96 \\
MDA-MB-231 & 1.73 & 0.45 & 1.63 & 0.43 & 0.88 & 2.16 & 1.76 & 0.70 \\
\hline & $17-\mathrm{AAG}$ & & $17-\mathrm{AEPGA}$ & & & $17-\mathrm{DMAG}$ & & \\
Cell line & $72 \mathrm{~h}(\mu \mathrm{M})$ & $\mathrm{SE}$ & $72 \mathrm{~h}(\mu \mathrm{M})$ & $\mathrm{SE}$ & P-value $^{\mathrm{a}}$ & $72 \mathrm{~h}(\mu \mathrm{M})$ & SE & P-value $^{\mathrm{a}}$ \\
\hline MCF-7 & 1.14 & 0.69 & 1.69 & 0.82 & 0.54 & 1.14 & 0.52 & 1.00 \\
SKBR-3 & 0.53 & 2.07 & 0.67 & 1.89 & 0.96 & 0.66 & 1.04 & 0.96 \\
MDA-MB-231 & 1.06 & 0.18 & 0.44 & 0.38 & 0.002 & 0.28 & 0.02 & 0.0001 \\
\hline
\end{tabular}

Calculated $\mathrm{GI}_{50}$ given in $\mu \mathrm{M}$, the SE and P-value compared to 17-AAG following the exposure of the MCF-7, SKBR-3 and MDA-MB-231 cell lines to 17-AAG, 17-AEPGA and 17-DMAG for 48 and $72 \mathrm{~h}$. aindicates significance according to the t-test. SE, standard error.

Bis (Bio-Rad Laboratories Inc., Hercules, CA, USA), $1.5 \mathrm{M}$ Tris buffer $\mathrm{pH} 8.8,10 \%$ SDS (Gibco), 10\% APS and TEMED (Bio-Rad Laboratories Inc.). For protein separation, SDS-PAGE was used, followed by the transfer onto a nitrocellulose membrane [Trans-Blot Transfer Medium, Pure Nitrocellulose Membrane $(0.45 \mu \mathrm{m})$; Bio-Rad Laboratories Inc.]. The blots were then incubated with antibodies and chemiluminescence was detected with SuperSignal West Dura Extended Duration Substrate (Pierce/Thermo Fisher Scientific Inc.). The following antibodies were used: anti-EGFR1 (Cat. no. 8083), anti-HER2 (Cat. no. 2242), anti-IGF1R (Cat. no. 3027), anti- $\beta$-catenin (Cat. no. 8480) (all from Cell Signaling Technology, Inc., Danvers, MA, USA), anti-HSP90 (Cat. no. ADI-SPA-831), anti-HSP70 (Cat. no. ADI-SPA-820) (both from Stressgen, San Diego, CA, USA), anti-HSP27 (Cat. no. 2402; Cell Signaling Technology, Inc.), anti-poly(ADP-ribose) polymerase (PARP) (Cat. no. sc-8007; Santa Cruz Biotechnology, Inc., Dallas, TX, USA), anti-cleaved PARP (Cat. no. 5625), anti-caspase-3 (Cat. no. 9662) and anti-cleaved caspase-3 (Cat. no. 9661) (all from Cell Signaling Technology, Inc.). Actin (Cat. no. A5441; Sigma Chemical Co.) was used as loading control.

Statistical analysis. QuickCals calculator for scientists (GraphPad Software, Inc., La Jolla, CA, USA) was used for statistical analysis. The Student's t-test was used to compare the means. To determine the $\mathrm{GI}_{50}$ values a 5-parameter logistic regression model was carried out using R software (The R Foundation for Statistical Computing, Vienna, Austria). Differences were considered statistically significant with two-tailed P-values $<0.05$.

\section{Results}

Cell doubling time. To determine a test confluence in which active cell proliferation is permitted during the experiments and also a sufficient confluence for the addition of the drug, the cell doubling time of each cancer cell line was first evaluated using different initial seeding densities and by following the cell growth for 7 days (data not shown). The doubling times for the MCF-7, SKBR-3 and MDA-MB-231 cancer cells were

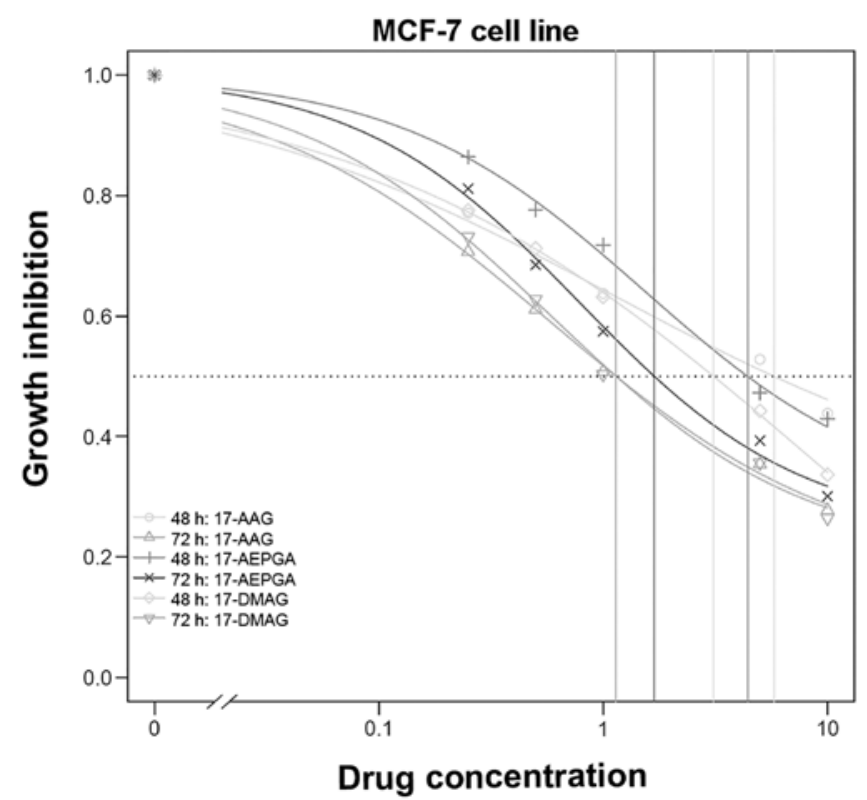

Figure 1. Results of proliferation assay for the MCF-7 cell line following treatment with indicated concentrations $(\mu \mathrm{M})$ of 17-AAG, 17-AEPGA and 17-DMAG for 48 and $72 \mathrm{~h}$

found to be $29 \pm 6,19 \pm 4$ and $23 \pm 7 \mathrm{~h}$, respectively. These data are consistent with the reported doubling times of the tested cells in the literature (21). To evaluate the dose- and time-dependent effects of HSP90 inhibitors on the tested cancer cell lines, each cell line was exposed to the drugs for 48 and $72 \mathrm{~h}$.

Cell proliferation assay and $G I_{50}$ value. Table I summarizes the results of MTT assay with all 3 tested cell lines and the 3 HSP90 inhibitors. We evaluated the required $\mathrm{GI}_{50}$ concentration for each cell line by MTT assay. All 3 tested BC cell lines were exposed to the specific HSP90 inhibitors for 48 and $72 \mathrm{~h}$, ensuring full coverage of at least 2 cell doubling times. The sensitivity to the HSP90 inhibitors differed in all cell lines and a dose- and timedependent effect was evident (Table I and Figs. 1-3). 


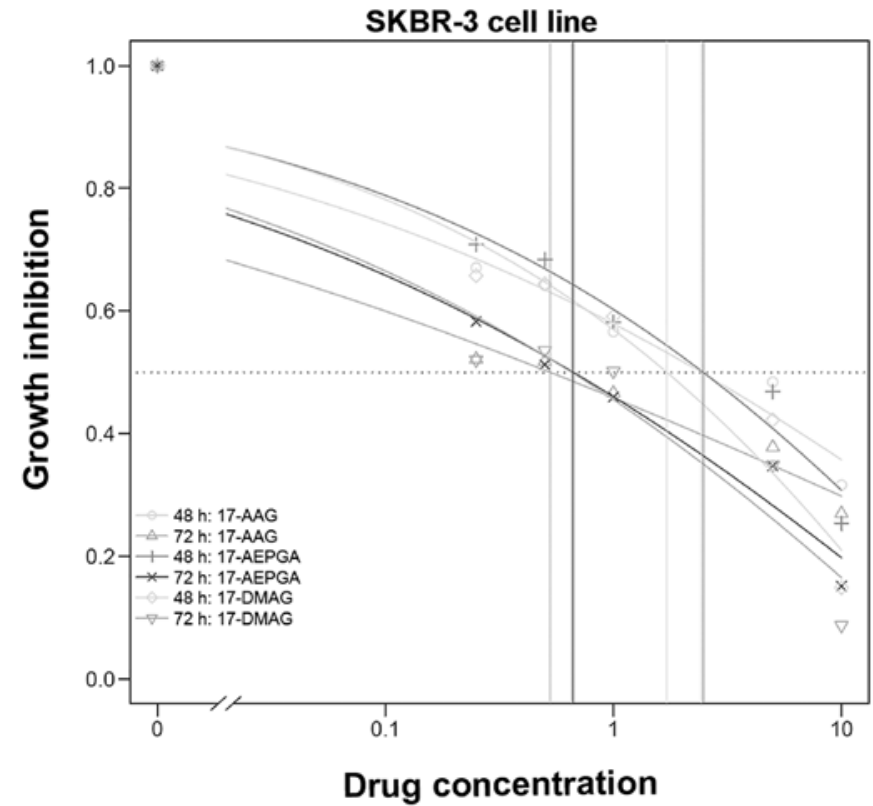

Figure 2. Results of proliferation assay for the SKBR-3 cell line following treatment with the indicated concentrations $(\mu \mathrm{M})$ of 17-AAG, 17-AEPGA and 17-DMAG for 48 and $72 \mathrm{~h}$

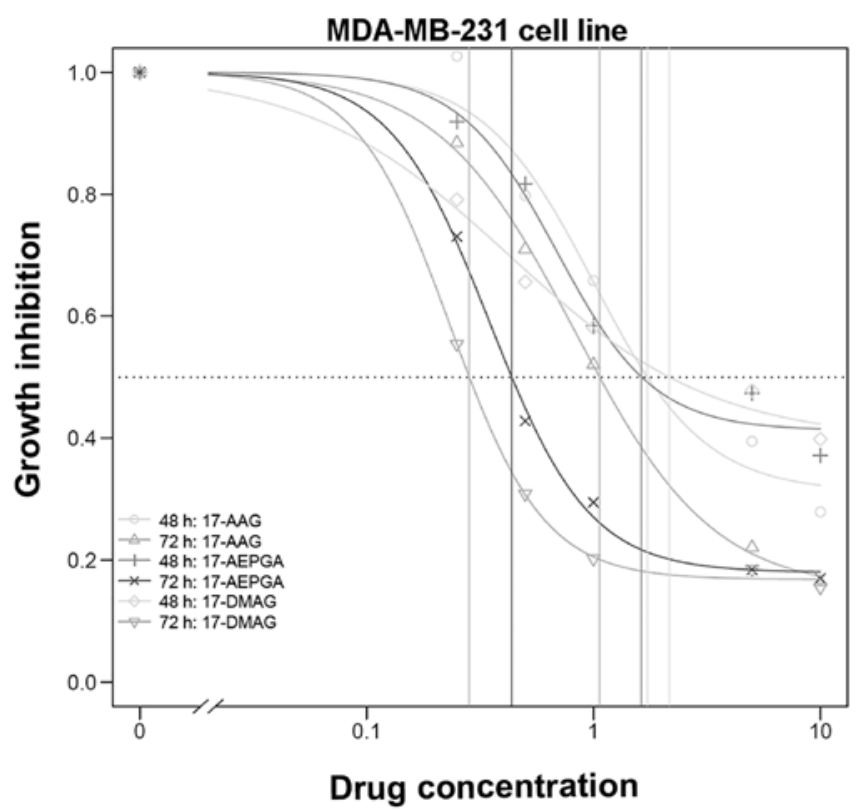

Figure 3. Results of proliferation assay for the MDA-MB-231 cell line following treatment with the indicated concentrations $(\mu \mathrm{M})$ of 17-AAG, 17-AEPGA and 17-DMAG for 48 and $72 \mathrm{~h}$.

In the MCF-7 cells, the required $\mathrm{GI}_{50}$ of $17-\mathrm{AAG}$ decreased $>50 \%$ when the cells were exposed for $72 \mathrm{~h}$ compared to $48 \mathrm{~h}$. The same trend was observed with 17-AEPGA and 17-DMAG in the MCF-7 cells (Table I); however the decrease did not reach statistical significance with all 3 tested derivates. No significant difference was observed when comparing the efficacy of 17-AAG, 17-DMAG and 17-AEPGA. Fig. 1 presents the proliferation assay results for the MCF-7 cells.

In the SKBR-3 cells as well, no significant time-dependent difference was observed for 17-AAG, 17-AEPGA and 17-DMAG (Table I and Fig. 2). In addition, in terms of efficacy,

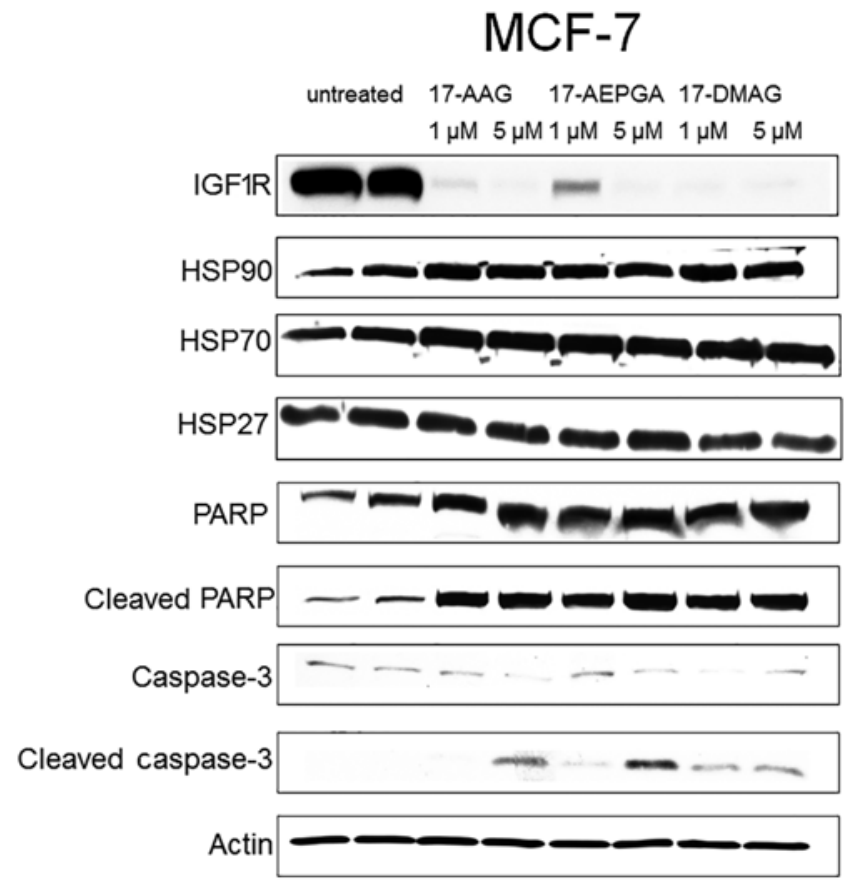

Figure 4. Results of western blot analysis demonstrating the expression of HER2, EGFR1 and IGF1R, HSP70, HSP27 and the presence of apoptosis in the treated compared to the untreated MCF-7 cells.

no significant differences between water-soluble 17-AEPGA and 17-DMAG compared to non-water-soluble 17-AAG were observed. Fig. 2 presents the results of the proliferation assay for the SKBR-3 cells.

In the MDA-MB-231 cells, a clear time-dependent effect was observed for 17-AEPGA ( $\mathrm{P}=0.01)$; the other inhibitors did not exhibit a significant difference. Furthermore, most significant differences in the efficacy of 17-AEPGA and 17-DMAG compared to that of 17-AAG were observed in the MDA-MB231 cell line. Highly significant differences following $72 \mathrm{~h}$ of exposure were observed between 17-AEPGA and 17-DMAG compared to 17-AAG, resulting in a $\mathrm{GI}_{50} \leq 1 \mu \mathrm{M}$; no differences were observed at $48 \mathrm{~h}$ of exposure. The MDA-MB-231 cells were found to be the most sensitive among all 3 tested cell lines (Table I and Fig. 3).

Inhibition of tumor progression and survival factors. All 3 cell lines were examined in terms of HER2, IGF1R and EGFR1 expression. However, HER2 was most highly expressed in the SKBR-3 cells, IGF1R was most highly expressed in the MCF-7 cells and EGFR1 was most highly expressed in the MDA-MB-231 cells. For western blot analysis, the highest expression of each factor in each cell line was analysed only.

Only $24 \mathrm{~h}$ of exposure to 17-AAG, 17-AEPGA and 17-DMAG resulted in the downregulation of the specific CP in all 3 tested cell lines (Figs. 4-6). This effect was already evident following exposure to the drugs at $1 \mu \mathrm{M}$, suggesting that HSP90 inhibition leads to the rapid impairment of post-translational processes within the cell. The expression of HER2 in the SKBR-3 cells, that of IGF1R in the MCF-7 cells and that of EGFR1 in the MDA-MB-231 cells was almost not detectable following treatment with the 3 tested HSP90 inhibitors in all 3 BC cell lines, as shown by western 


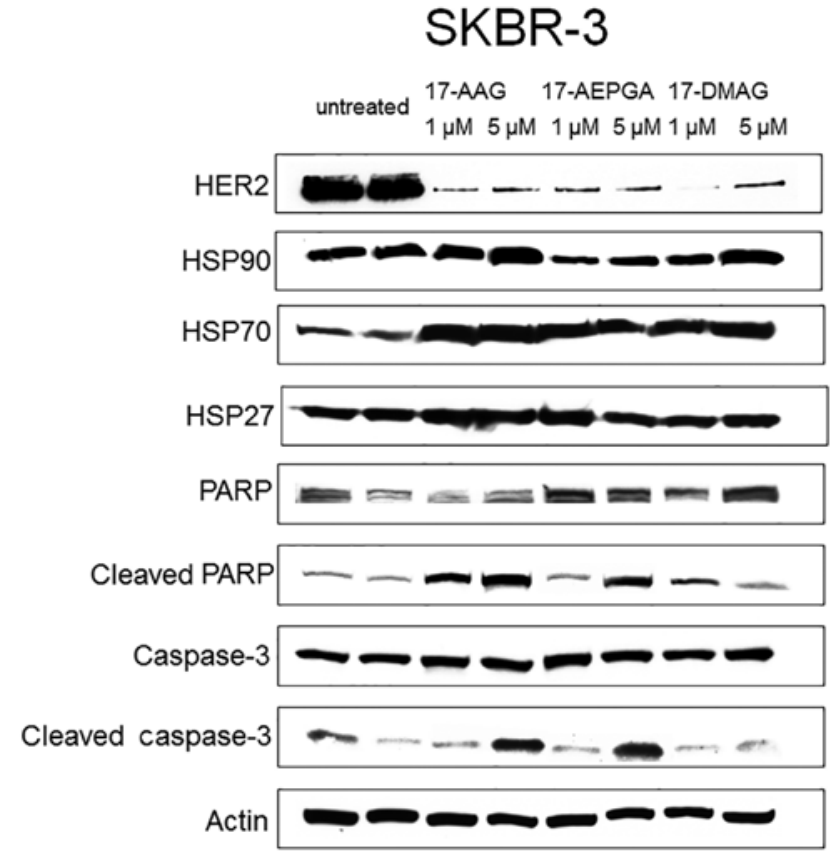

Figure 5. Results of western blot analysis demonstrating the expression of HER2, EGFR1 and IGF1R, HSP70, HSP27 and the presence of apoptosis in the treated compared to the untreated SKBR-3 cells.

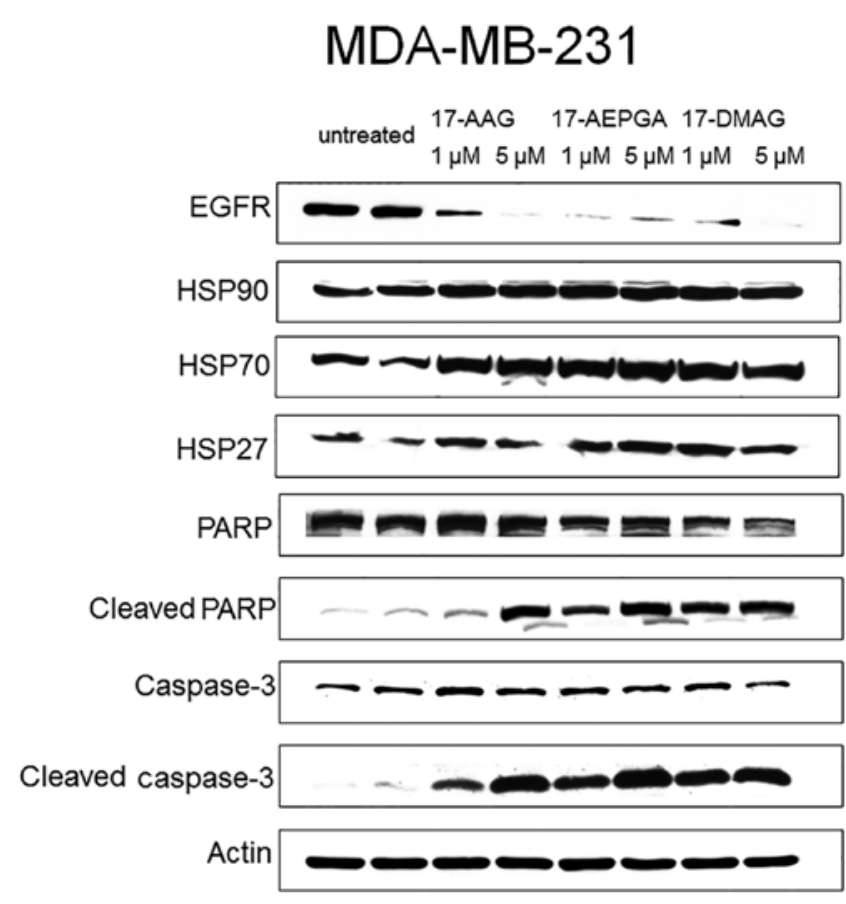

Figure 6. Results of western blot analysis demonstrating the expression of HER2, EGFR1 and IGFR1, HSP70, HSP27 and the presence of apoptosis in the treated compared to the untreated MDA-MB-231 cells.

blot analysis (Figs. 4-6). By contrast, the expression of HER2, EGFR1 and IGF1R was not affected in the untreated cells (Figs. 4-6). Parallel to the inhibition of the expression of CPs in the treated cells, apoptosis was also already present following exposure to the drugs at $1 \mu \mathrm{M}$ in all 3 cell lines (Figs. 4-6). Apoptosis was evaluated by the cleavage of caspase-3 and PARP. The blots in Figs. 4-6 demonstrate that caspase-3 and PARP cleavage products were detected in all 3 cell lines following treatment with 17-AAG, 17-AEPGA and 17-DMAG. By contrast, in the untreated cells, cleavage products were not significantly detectable. HSP90 protein itself was not affected by HSP90 inhibition, as 17-AAG, 17-AEPGA and 17-DMAG resulted only in functional HSP90 inhibition. As a hallmark of successful HSP90 inhibition, HSP70 expression was upregulated in all 3 cell lines. The expression of HSP27, a small chaperone that is known to correlate with a poor $\mathrm{BC}$ outcome and more aggressive breast tumors, was also analysed. However, no significant differences in HSP27 expression were observed in any cell line (Figs. 4-6).

\section{Discussion}

Since the introduction of molecular profiling and targeted therapy, the concept of neoadjuvant and adjuvant therapy in $\mathrm{BC}$ has changed dramatically. In particular, prognostic and predictive factors have been identified on the basis of molecular genetics. ER and HER2 overexpression in BC are a paradigm for targeted therapy (4). The targeted therapy approach however, is severely limited by acquired resistance in the clinic. Such resistance is often mediated by the crosslinkage between the different signaling pathways that are crucial for the survival of $\mathrm{BC}$ cells and are dependent upon proteins, including kinases, growth receptors and hormones.

All these factors have a common pivotal point when passing through the post-translational modification process. To attain the functional active mature protein structure, all these factors require HSP90 (22). HSP90, as an ubiquitously expressed chaperone, represents an important therapeutic target in the treatment of $\mathrm{BC}(23)$.

Apart from the dependency of the CP upon HSP90, the selective inhibition of HSP90 in tumor cells alone due to much the higher activity of HSP90 in tumor cells represents an additional attribute of this promising target in oncology (24). The natural ansamycin antibiotic, geldanamycin, belongs to the group of HSP90 inhibitors; however, it cannot be used clinically due to unacceptable hepatotoxicity. However, its well-known semi-synthetic derivate, 17-AAG, is currently undergoing phase II/III clinical trials in BC and other malignancies (https:// clinicaltrials.gov/ct2/results?term=Tanespimycin $+\&$ Search= Search). Tanespimycin (17-AAG derivate) has demonstrated promising antitumor activity and tolerability in a phase II trial in patients with HER2-positive metastatic breast cancer, when administered in combination with trastuzumab (Herceptin ${ }^{\circledR}$ ) in patients whose disease progressed following treatment with trastuzumab alone. Although the overall noted antitumor activity was only moderate, the present study represents the first of its kind, addressing tumor regression in solid tumors by HSP90 inhibition $(25,26)$. As regards other cancer types, such as multiple myeloma, tanespimycin has also shown promising results in a phase $\mathrm{Ib}$ dose-escalating trial in combination with bortezomib (27). Based on these findings, tanespimycin has been granted orphan drug status in the US and Europe.

Another formulation of the 17-AAG-based HSP90 inhibitor was shown to have antitumor effects in gastrointestinal and stromal tumors (GIST) and non-small cell lung cancer (NSCLC) (retaspimycin) (28). However, most of the clinical trials with geldanamycin-based HSP90 inhibitors 
have been carried out with 17-AAG formulations, resulting in difficulties in the delivery of the compound in the clinic due to the lack of water-solubility in physiological fluids. Thus, the water-soluble derivatives, 17-DMAG and 17-AEPGA, were developed. 17-DMAG has been tested in some phase I studies (29-31); to the best of our knowledge, no clinical study with 17-AEPGA has been published to date.

We have been able to demonstrate that in vitro, the water-soluble geldanamycin derivates, 17-DMAG and 17-AEPGA, are equally effective or superior compared to 17-AAG. The calculated $\mathrm{GI}_{50}$ value was comparable to that of 17-AAG in all 3 cell lines and was significantly lower in the MDA-MB-31 cells (Table I). Our GI $_{50}$ calculations are consistent with the reported values in the literature $(15,16)$.

Treatment of all 3 tested human BC cell lines for $48 \mathrm{~h}$ with 17-DMAG, 17-AEPGA and 17-AAG demonstrated a significant anti-proliferative effect (Figs. 1-3). Prolongation of the treatment period up to $72 \mathrm{~h}$ resulted in a decrease in the required $\mathrm{GI}_{50}$ (Table I). A possible explanation for this finding may be that only proteins that are in the process of post-translational modification are inhibited and redirected to proteosomal degradation by HSP90 inhibition. By contrast, already pre-existing functional mature proteins are not affected by HSP90 inhibition. Consequently, not all signaling pathways crucial for cell survival are affected simultaneously so that crosslinks between the different signaling pathways may act complementary in the initial phase, but are severely hampered when particular amounts of protein and or numbers of signaling pathways are downregulated within the cancer cell. In addition, in our experiments, the cells were not cell cycle-synchronized, so that treatment for $72 \mathrm{~h}$, assuring two cell cycle doubling times of exposure to HSP90 inhibitors, ensured that all cells were affected by HSP90 inhibition. Although the anti-proliferative effects become evident with a delay, the detrimental alterations at the molecular level were evident as soon as $24 \mathrm{~h}$ and at very low concentrations as shown by the results of western blot analysis (Figs. 4-6).

In BC cells, tyrosine kinases, such as IGF1R, EGFR1 and HER 2 comprise a major oncogene family being responsible for tumor progression and growth. The molecular profiling revealed that all 3 cell lines expressed IGF1R, HER2 and EGFR1. For western blot analysis, however, the experiments were limited to the most significantly expressed tyrosine kinase. IGF1R was most highly expressed in the MCF-7 cells, EGFR1 was most highly expressed in the MDA-MB-231 cells and HER2 was most highly expressed in the SKBR-3 BC cells. Although in the proliferation assay a significant inhibition of proliferation was observed in the MCF-7, SKBR-3 and MDA-MB-231 cells following $48 \mathrm{~h}$ of exposure at higher concentrations, the results of western blot analysis, however, demonstrated that at the molecular level, significant alterations in the expression profiles of the tested CPs already began to take effect at the concentration of $1 \mu \mathrm{M}$ for each tested inhibitor. Furthermore, apoptosis was also already present at the concentration of $1 \mu \mathrm{M}$ in all cell lines, as proven by caspase-3 and PARP assay (Figs. 4-6).

As a hallmark of successful HSP90 inhibition, HSP70 was equally upregulated in all 3 cell lines following treatment. Despite our encouraging results with the water-soluble compounds, the upregulation of HSP70 remains a challenging problem for the application of HSP90 inhibitors in the clinic. HSP70 functions as a chaperone itself. In the multi-HSP90 chaperon complex,
HSP70 recruits substrate-. However with its anti-apoptotic and cytoprotective properties, HSP70 promotes cancer cell survival and is also active in the absence of HSP90. Furthermore, HSP70 has also been shown to correlate with malignant transformation and growth (32). Sun et al demonstrated that in triple negative BC, HSP70 significantly correlates with tumor aggressiveness in terms of metastatic potential (33). In addition, HSP70 is also known to interact with the ligand-binding domain of steroid hormone receptors and chaperoning their maturation, as well as the translocation of these receptors from the cytosol to the nucleus (34). This function of HSP70 could be fatal and boost hormone-sensitive tumor cells. These findings indicate that the utilization of HSP90 inhibitors as single agents in the treatment of $\mathrm{BC}$ is inherent with the danger of possible switching to a more aggressive tumor biology.

HSP27 is also known to be overexpressed in BC and has been associated with decreased survival, lymph node positivity and resistance to chemotherapy (35). Recently, trastuzumabresistant BC cells were found to overexpress HSP27. We found that HSP27 expression was not affected by HSP90 inhibition. However, it remains an additional target in the treatment of BC, as studies using have siRNA demonstrated encouraging results in terms of the apoptosis and chemosensitivity of HSP27overexpressing BC cells (36).

In conclusion, our data suggest that HSP90 may be a promising target in the treatment of BC and the newly available water-soluble derivates have equal or superior anti-proliferative effects to those of 17-AAG. The downregulation of CPs and the induction of apoptosis was observed following treatment with 17-AAG, 17-AEPGA and 17-DMAG from the concentration of $1 \mu \mathrm{M}$. HSP27 expression was not affected, but HSP70 was upregulated by all 3 tested HSP90 inhibitors. The new water-soluble derivate may help to overcome the difficulties associated with the delivery of the drugs in the clinic. Further studies are required to test the bioavailability of the new watersoluble derivates in vivo. Combination studies with HSP90 inhibitors and other target-therapies and or chemotherapy are essential to address the utility of HSP90 inhibition in BC treatment as a single administration is afflicted with molecular alterations that may be fatal. Further studies and research are warranted to find strategies to counteract HSP70 and HSP27 in $\mathrm{BC}$.

\section{References}

1. Sainsbury R: The development of endocrine therapy for women with breast cancer. Cancer Treat Rev 39: 507-517, 2013.

2. Mittendorf EA, Wu Y, Scaltriti M, Meric-Bernstam F, Hunt KK, Dawood S, Esteva FJ, Buzdar AU, Chen H, Eksambi S, et al: Loss of HER2 amplification following trastuzumab-based neoadjuvant systemic therapy and survival outcomes. Clin Cancer Res 15: 7381-7388, 2009.

3. Scaltriti M, Eichhorn PJ, Cortés J, Prudkin L, Aura C, Jiménez J, Chandarlapaty S, Serra V, Prat A, Ibrahim YH, et al: Cyclin E amplification/overexpression is a mechanism of trastuzumab resistance in HER $2^{+}$breast cancer patients. Proc Natl Acad Sci USA 108: 3761-3766, 2011.

4. Burrows F, Zhang $\mathrm{H}$ and Kamal A: Hsp90 activation and cell cycle regulation. Cell Cycle 3: 1530-1536, 2004.

5. Whitesell L and Lindquist SL: HSP90 and the chaperoning of cancer. Nat Rev Cancer 5: 761-772, 2005.

6. Zajac M, Gomez G, Benitez J and Martínez-Delgado B: Molecular signature of response and potential pathways related to resistance to the HSP90 inhibitor, 17AAG, in breast cancer. BMC Med Genomics 3: 44, 2010. 
7. Basso AD, Solit DB, Munster PN and Rosen N: Ansamycin antibiotics inhibit Akt activation and cyclin $\mathrm{D}$ expression in breast cancer cells that overexpress HER2. Oncogene 21: 1159-1166, 2002.

8. Song CH, Park SY, Eom KY, Kim JH, Kim SW, Kim JS and Kim IA: Potential prognostic value of heat-shock protein 90 in the presence of phosphatidylinositol-3-kinase overexpression or loss of PTEN, in invasive breast cancers. Breast Cancer Res 12: R20, 2010

9. Prodromou C and Pearl LH: Structure and functional relationships of Hsp90. Curr Cancer Drug Targets 3: 301-323, 2003.

10. Powers MV and Workman P: Targeting of multiple signalling pathways by heat shock protein 90 molecular chaperone inhibitors. Endocr Relat Cancer 13 (Suppl 1): S125-S135, 2006.

11. Hollingshead M, Alley M, Burger AM, Borgel S, Pacula-Cox C, Fiebig HH and Sausville EA: In vivo antitumor efficacy of 17-DMAG (17-dimethylaminoethylamino-17-demethoxygeldanamycin hydrochloride), a water-soluble geldanamycin derivative. Cancer Chemother Pharmacol 56: 115-125, 2005.

12. Smith V, Sausville EA, Camalier RF, Fiebig $\mathrm{HH}$ and Burger AM: Comparison of 17-dimethylaminoethylamino-17-demethoxy-geldanamycin (17DMAG) and 17-allylamino-17-demethoxygeldanamycin (17AAG) in vitro: Effects on Hsp90 and client proteins in melanoma models. Cancer Chemother Pharmacol 56: 126-137, 2005.

13. Salomon DS, Brandt R, Ciardiello F and Normanno N: Epidermal growth factor-related peptides and their receptors in human malignancies. Crit Rev Oncol Hematol 19: 183-232, 1995.

14. Yerushalmi R, Gelmon KA, Leung S, Gao D, Cheang M, Pollak M, Turashvili G, Gilks BC and Kennecke H: Insulin-like growth factor receptor (IGF-1R) in breast cancer subtypes. Breast Cancer Res Treat 132: 131-142, 2012.

15. Sieuwerts AM, Klijn JG, Peters HA and Foekens JA: The MTT tetrazolium salt assay scrutinized: how to use this assay reliably to measure metabolic activity of cell cultures in vitro for the assessment of growth characteristics, IC50-values and cell survival. Eur J Clin Chem Clin Biochem 33: 813-823, 1995.

16. Jhaveri K, Taldone T, Modi S and Chiosis G: Advances in the clinical development of heat shock protein 90 (Hsp90) inhibitors in cancers. Biochim Biophys Acta 1823: 742-755, 2012.

17. Miyata $Y$, Nakamoto $H$ and Neckers L: The therapeutic target Hsp90 and cancer hallmarks. Curr Pharm Des 19: 347-365, 2013.

18. Ochel HJ, Eichhorn K and Gademann G: Geldanamycin: The prototype of a class of antitumor drugs targeting the heat shock protein 90 family of molecular chaperones. Cell Stress Chaperones 6: 105-112, 2001

19. Modi S, Stopeck AT, Gordon MS, Mendelson D, Solit DB, Bagatell R, Ma W, Wheler J, Rosen N, Norton L, et al: Combination of trastuzumab and tanespimycin (17-AAG, KOS-953) is safe and active in trastuzumab-refractory HER-2 overexpressing breast cancer: A phase I dose-escalation study. J Clin Oncol 25: 5410-5417, 2007.

20. Modi S, Stopeck A, Linden H, Solit D, Chandarlapaty S, Rosen N, D'Andrea G, Dickler M, Moynahan ME, Sugarman S, et al: HSP90 inhibition is effective in breast cancer: a phase II trial of tanespimycin (17-AAG) plus trastuzumab in patients with HER2positive metastatic breast cancer progressing on trastuzumab. Clin Cancer Res 17: 5132-5139, 2011.
21. Richardson PG, Chanan-Khan AA, Lonial S, Krishnan AY, Carroll MP, Alsina M, Albitar M, Berman D, Messina M and Anderson KC: Tanespimycin and bortezomib combination treatment in patients with relapsed or relapsed and refractory multiple myeloma: Results of a phase 1/2 study. Br J Haematol 153: 729-740, 2011.

22. Wagner AJ, Chugh R, Rosen LS, Morgan JA, George S, Gordon M, Dunbar J, Normant E, Grayzel D and Demetri GD: A phase I study of the HSP90 inhibitor retaspimycin hydrochloride (IPI-504) in patients with gastrointestinal stromal tumors or softtissue sarcomas. Clin Cancer Res 19: 6020-6029, 2013.

23. Ramanathan RK, Egorin MJ, Erlichman C, Remick SC, Ramalingam SS, Naret C, Holleran JL, TenEyck CJ, Ivy SP and Belani CP: Phase I pharmacokinetic and pharmacodynamic study of 17-dimethylaminoethylamino-17-demethoxygeldanamycin, an inhibitor of heat-shock protein 90 , in patients with advanced solid tumors. J Clin Oncol 28: 1520-1526, 2010.

24. Jhaveri K, Miller K, Rosen L, Schneider B, Chap L, Hannah A, Zhong Z, Ma W, Hudis C and Modi S: A phase I dose-escalation trial of trastuzumab and alvespimycin hydrochloride (KOS-1022; 17 DMAG) in the treatment of advanced solid tumors. Clin Cancer Res 18: 5090-5098, 2012.

25. Pacey S, Wilson RH, Walton M, Eatock MM, Hardcastle A, Zetterlund A, Arkenau HT, Moreno-Farre J, Banerji U, Roels B, et al: A phase I study of the heat shock protein 90 inhibitor alvespimycin (17-DMAG) given intravenously to patients with advanced solid tumors. Clin Cancer Res 17: 1561-1570, 2011.

26. Mosser DD, Caron AW, Bourget L, Denis-Larose C and Massie B: Role of the human heat shock protein hsp70 in protection against stress-induced apoptosis. Mol Cell Biol 17: 5317-5327, 1997.

27. Sun B, Zhang S, Zhang D, Li Y, Zhao X, Luo Y and Guo Y: Identification of metastasis-related proteins and their clinical relevance to triple-negative human breast cancer. Clin Cancer Res 14: 7050-7059, 2008.

28. Daniel S, Bradley G, Longshaw VM, Söti C, Csermely P and Blatch GL: Nuclear translocation of the phosphoprotein Hop (Hsp70/Hsp90 organizing protein) occurs under heat shock, and its proposed nuclear localization signal is involved in Hsp90 binding. Biochim Biophys Acta 1783: 1003-1014, 2008.

29. Hansen RK, Parra I, Lemieux P, Oesterreich S, Hilsenbeck SG and Fuqua SA: Hsp27 overexpression inhibits doxorubicininduced apoptosis in human breast cancer cells. Breast Cancer Res Treat 56: 187-196, 1999.

30. Kang SH, Kang KW, Kim KH, Kwon B, Kim SK, Lee HY, Kong SY, Lee ES, Jang SG and Yoo BC: Upregulated HSP27 in human breast cancer cells reduces Herceptin susceptibility by increasing Her2 protein stability. BMC Cancer 8: 286, 2008. 